\title{
Carcinoma of Penis with Metastasis to Right Breast
}

\author{
Sajal Goel ${ }^{1}$ Deepak Kumar Mittal ${ }^{1} \quad$ Pankaj Sharma $^{2}$ \\ ${ }^{1}$ Department of Clinical Oncology, Delhi State Cancer Institute, \\ Delhi, India \\ 2Department of Radiodiagnosis, Delhi State Cancer Institute, Delhi, \\ India
}

\begin{abstract}
Address for correspondence Sajal Goel, MBBS, DNB, Department of Clinical Oncology, Delhi State Cancer Institute (GNCT of Delhi), Dilshad Garden, Delhi -110095, India (e-mail: sajal.goel@yahoo.com).
\end{abstract}

Asian J Oncol 2019;5:82-85

\begin{abstract}
Keywords

- developing world

- squamous

- penile cancer

- lesion in right breast

Penile cancer is relatively frequent in developing world compared with developed countries. Majority of histologies are of squamous origin and spread through lymphatics or vascular channels. Metastases from penile carcinoma mainly involves lung, liver, bone, and rarely other sites. The patient reported here is a treated case of penile cancer who presented with lesion in right breast after treatment for primary disease. He responded well to the adjuvant therapy.
\end{abstract}

\section{Introduction}

Cutaneous metastases are external manifestations of internal malignancy. The incidence varies but can be up to $10 \%{ }^{1}$ They may appear as single or multiple, painless, small-circumscribed swellings of varied appearances or a large infiltrative mass. ${ }^{2}$ Breast, lung, gastrointestinal tract, upper aerodigestive tract, uterus, and kidney commonly contribute to skin lesions. ${ }^{2,3}$ These lesions may present after direct, lymphatic, or hematogenous spread. ${ }^{4}$ The nature of treatment offered to cutaneous metastases is mostly palliative in the form of chemotherapy, radiotherapy, local excision, laser, photodynamic therapy, cryotherapy, immune response modifier, such as imiquimod, etc. ${ }^{4}$ Whatever the treatment offers, prognosis remains poor and overall survival is typically 3 months. ${ }^{5}$

We hereby report a case of penile cancer whose breast lesion appears more than 6 months after primary surgery and postoperative radiation. To the best of our knowledge, this is the second reported case. ${ }^{6}$ The lesion in this case involved right breast on clinical and radiological examination but was proven as skin metastasis pathologically. The biopsy proved it a deposit of invasive moderately differentiated squamous cell carcinoma, not originating from overlying skin.

\section{Case History}

A 75-year-old HIV negative male, biopsy-proven case of poorly differentiated squamous cell carcinoma of glans penis extending distally to shaft with bilateral inguinal nodes, underwent total penile amputation with bilateral inguinal and iliac lymphadenectomy. On gross examination, an ulceroproliferative growth of $5 \mathrm{~cm} \times 4 \mathrm{~cm}$ size involved penile shaft and prepuce, partially destroying the septum, and corpus cavernosum. Two out of five left and three out of nine right inguinal nodes were positive. Three left and four right iliac lymph nodes were reactive. Microscopic examination revealed a tumor infiltrating into corpus cavernosum with moderate peritumoral lymphocytic reaction and absent vascular invasion; all margins, urethra and testis free, poorly differentiated squamous cell carcinoma, and pT2N2cM0 (Stage IIIb). ${ }^{7}$ He received external beam radiotherapy to a dose of $60 \mathrm{~Gy} / 33$ fractions/7 weeks. The disease-free interval was 6 months.

Later he presented to us with an erythematous hard periareolar swelling lying in outer quadrant of right breast since 1-month. Bilateral nipples were preserved and no axillary lymph nodes were palpable. Ultrasound showed it as abscess and fine needle aspiration cytology was negative. Within 1.5 months, it progressed to a $6 \mathrm{~cm} \times 6 \mathrm{~cm}$ size crater shaped lesion. Whole body (WB) positron emission tomography-computed tomography (PET-CT) scan showed a metabolically active swelling in right breast, a nodular lesion in lower lobe of right lung (-Fig. 1A), and a viable lesion involving bladder wall. Biopsy from breast lesion (-Fig. 2) showed skin deposit of invasive moderately differentiated squamous cell carcinoma, not originating from overlying skin. Cystoscopy ruled out metastases in urinary bladder and urethra. This disease was staged as carcinoma penis post-op yprT2N2M1 (stage IV) with recurrence in skin of right breast. ${ }^{7}$ He received three weekly adjuvant chemotherapy with CEP-VB regime (cyclophosphamide $700 \mathrm{mg}$, received

September 24, 2019

accepted

October 23, 2019
Dol https://doi.org/

$10.1055 / \mathrm{s}-0039-3400734$

ISSN 2454-6798.
(C)2019 Spring Hope Cancer

Foundation \& Young Oncologist

Group of Asia
License terms

(ㅇ) (1) $\Theta \circledast$ 


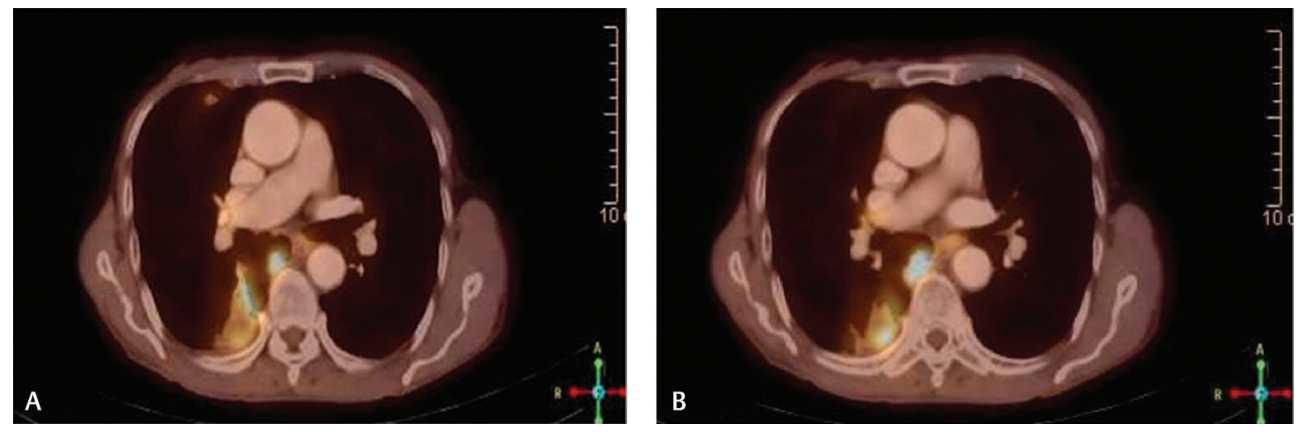

Fig. 1 (A, B) PET-CT fusion images showing well-defined fluorodeoxyglucose avid lesion involving apical segment of lower lobe parenchyma of right lung suggestive of metastases. PET-CT, positron emission tomography-computed tomography.

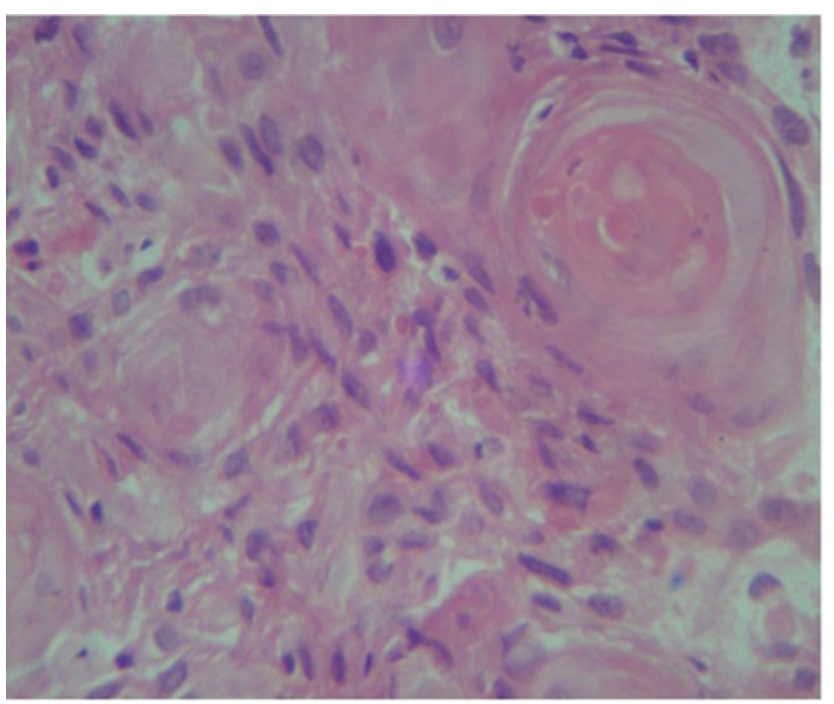

Fig. 2 Biopsy review from breast lesion showing the characteristic "keratin pearl" deposit of invasive moderately differentiated squamous cell carcinoma, not originating from overlying skin.

epirubicin $60 \mathrm{mg}$, cisplatin $60 \mathrm{mg}$ on day 1 and vincristine $1.5 \mathrm{mg}$, bleomycin 15 units on day 11).

Breast mass and right lung lesions ( - Fig. 1) completely and metabolically resolved after four and seven cycles, respectively. He received locoregional radiation to right chest wall to a dose of $50 \mathrm{~Gy} / 20$ fractions/30 days along with tablet geftinib $250 \mathrm{mg}$ once a day. Follow-up contrast-enhanced computed tomography (CECT) of chest, abdomen, and pelvis ( - Fig. 3) was normal. The patient followed-up for 1.5 years. On telephonic interrogation, he succumbed to death due to traumatic hip fracture after a total duration of 2 years.

\section{Discussion}

The incidence of penile cancer is lowest in Jews, rare in America and Europe, but common in Asia, Africa, and South America. ${ }^{8}$ India (rural > urban) has one of the highest world incidences of penile cancer with rates up to 3.32 per 100,000 men in some regions. ${ }^{9}$ The high incidence is attributed to uncommon practice of circumcision, poor hygiene, phimosis, multiple sexual partners, human papilloma virus (HPV) and human immunodeficiency virus (HIV) infection, and exposure to tobacco. ${ }^{10}$ It is primarily an old-age disease but can occur in younger individuals as well. ${ }^{10}$ Patients present at advanced age because of embarrassment and lack of access to specialized health care. ${ }^{10}$ In our case, old age, absence of circumcision, and poor hygiene were the contributory factors.

The tumor may arise from prepuce, glans, coronal sulcus, or penile shaft. ${ }^{11}$ In our case, the tumor originated from penile shaft and involved prepuce. It can be morphologically exophytic, nodular or ulcerative. ${ }^{11}$ Our patient presented with an ulceroproliferative disease. Penile cancer can spread directly, by lymphatic or hematogenous routes. ${ }^{11}$ The rate of nodal metastases is between 40 and $50 \% .^{12}$ Our patient had bilateral inguinal lymph nodal metastases, both positive for malignancy and reactive bilateral iliac lymphadenopathy.

Distant metastasis in penile cancer is rare (incidence $1-10 \%$ ) and occurs in presence of advanced locoregional disease. ${ }^{13,14}$ The review of literature of anecdotal reports suggests metastasis of penile cancer to lungs, liver, brain, skeleton, heart, retroperitoneum, skin of neck, and breast..$^{6,13,15-19}$ In the first reported case of breast metastasis, the patient presented with a 2-cm irregular shaped lump, palpable near his left nipple. ${ }^{6}$ The patient reported here, presented to us with an erythematous hard periareolar swelling lying in outer quadrant of right breast. In both the cases, axillary lymph nodes were not palpable ${ }^{6}$ (present case). In our case, both the nipples were preserved.

The patient seems fairly well managed outside for primary disease with surgery and adjuvant radiation. For metastatic disease of penis, treatment has not been established because of lack of clinical trials. Combination chemotherapy seems to be an effective modality. Dexeus et al used methotrexate, bleomycin, and cisplatin combination..$^{20}$ Trabulsi and Hoffman-Censits and Hakenberg and Protzel had used multiagent cisplatin-based combinations..$^{21,22}$ Pizzocaro et al have used taxanes with cisplatin and fluorouracil. ${ }^{23}$ Some centers have tried targeted therapy alone or in combination with chemotherapy. ${ }^{21,22}$ Our patient was also given combination chemotherapy with CEP-VB regime to which he responded completely. He further received local chest-wall irradiation and systemic oral tyrosine kinase inhibitor.

The data review of American Cancer Society reveals 5 -year relative survival rate for penile cancer with localized, regional, and distant disease as $82,48 \%$ and not 

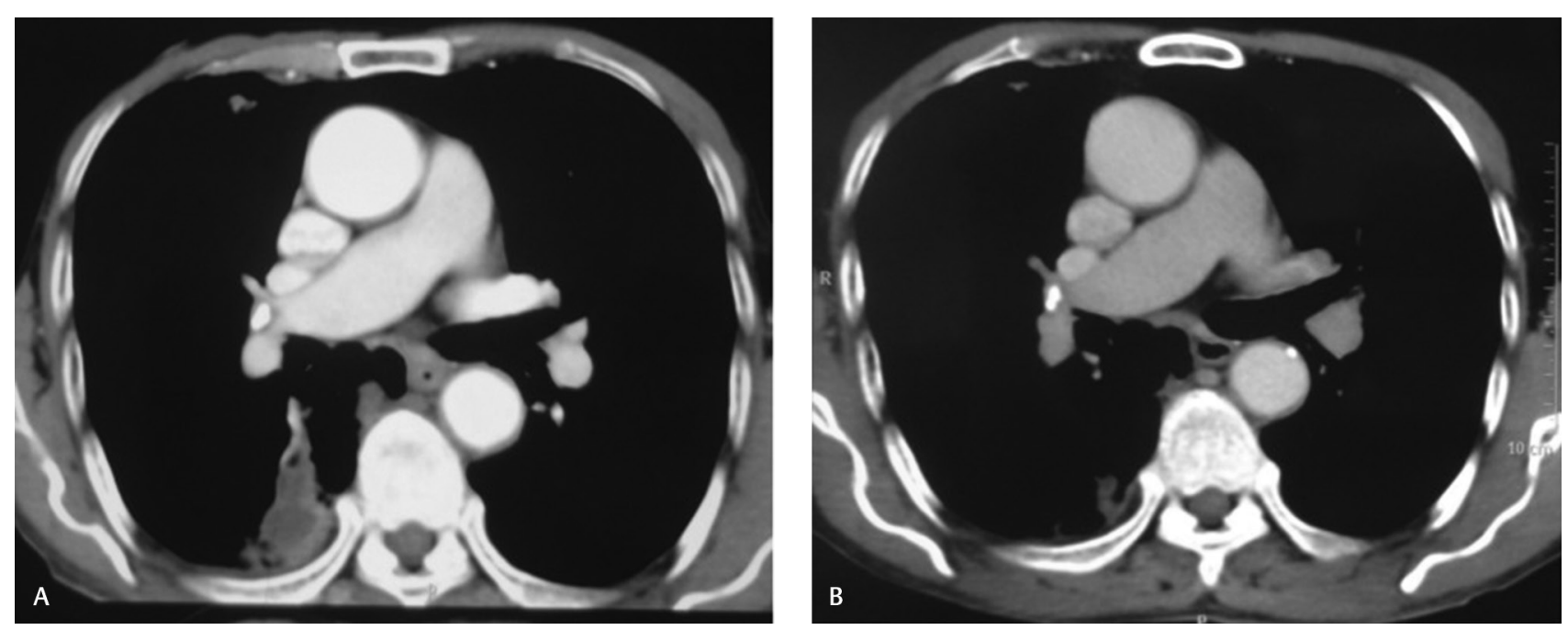

Fig. 3 (A and B) Comparison of CT images at presentation and 6 months posttreatment showing resolution of metastatic lesion involving apical segment of lower lobe parenchyma of right lung. CT, computed tomography.

available, respectively. ${ }^{24}$ Our patient followed up with us for 1.5 years. His scans were normal. He died due to nononcological cause.

\section{Conclusion}

It can be concluded that the data pertaining to metastases from penile cancer to unusual sites is sparse and cases are limited. This case highlights the importance of rarity of disease, associated morbidity, rare site of metastasis, and use of combination chemotherapy for management. We believe that our patient fought well, in spite of having advanced disease.

The limitation of present data are that the physicians reporting this case are not the ones who encountered this case at his first visit. This is also highlighted from the fact that only the biopsy evidence of disease from the breast is available, and no clinical image can be provided. But physicians have definitely witnessed his morbidity and supported him with all the compassion and care he deserved.

\section{Note}

This report was presented at the 1 st Indian Cancer Congress 2013, AROI (Abstract ID: 720, Genitourinary Oncology), Delhi on November 23, 2013.

\section{Conflict of Interest}

None declared.

\section{Acknowledgment}

The authors acknowledge Dr. Dhruv Jain, Department of Pathology, DSCI for pathological diagnosis.

\section{References}

1 Lookingbill DP, Spangler N, Helm KF. Cutaneous metastases in patients with metastatic carcinoma: a retrospective study of 4020 patients. J Am Acad Dermatol 1993;29(2, Pt 1):228-236

2 Marcoval J, Moreno A, Peyrí J. Cutaneous infiltration by cancer. J Am Acad Dermatol 2007;57(4):577-580
3 Schwartz RA. Cutaneous metastasis disease. J Am Acad Dermatol 1995;33(2 Pt 1):161-185

4 Cox NH, Coulson IH. Systemic disease and skin. In: Burns T, Breathnach S, Cox N, Griffiths C, eds. Rook's Textbook of Dermatology. 8th ed., vol. 3. Oxford: Wiley Blackwell Scientific Publications; 2010:62.17-62.19

5 Reingold IM. Cutaneous metastases from internal carcinoma. Cancer 1966;19(2):162-168

6 Franceschini G, Sanchez AM, Di Leone A, et al. Penile cancer metastasizing to the breast: a case report. J Med Case Reports 2016;10:53

7 Amin MB, Edge SB, Greene FL, et al, eds. AJCC Cancer Staging Manual. 8th edition. 2017;701-714

8 Hakenberg OW, Compérat E, Minhas S, Necchi A, Protzel C, Watkin N. EAU Guidelines on Penile Cancer. Eur Urol 2015;67(1):142-150

9 Montes Cardona CE, García-Perdomo HA. Incidence of penile cancer worldwide: systematic review and meta-analysis. Rev Panam Salud Publica. 2017;41:e117

10 Pahwa M, Girotra M, Rautela A, Abrahim R. Penile cancer in India: a clinicoepidemiological study. Gulf J Oncolog 2012; (12):7-10

11 Khandpur S, Reddy BS, Kaur H. Multiple cutaneous metastases from carcinoma of the penis. J Dermatol 2002;29(5):296-299

12 Pizzocaro G, Piva L, Bandieramonte G, Tana S. Up-to-date management of carcinoma of the penis. Eur Urol 1997;32(1):5-15

13 Burgers JK, Badalament RA, Drago JR. Penile cancer. Clinical presentation, diagnosis, and staging. Urol Clin North Am 1992;19(2):247-256

14 Staubitz WJ, Lent MH, Oberkircher OJ. Carcinoma of the penis. Cancer 1955;8(2):371-378

15 Riveros M, Gorostiaga R. Cancer of the penis. Arch Surg 1962;85:377-382

16 Lal P, Halder S, Datta NR. Carcinoma of the penis metastasizing to the dorsal spine. A case report. Urol Int 1999;62(4):249-251

17 Braumann L, Tsagozis P, Wedin R, Brosjö O. Femoral metastasis from penile carcinoma: report of 2 cases. Case Rep Urol. 2015; 2015:1-3

18 Swierz J, Poznański J, Stawarz B. Metastasis of penile cancer to the heart in a 20 -year-old patient. Wiad Lek 1992;45(7-8):314-316

19 Shaw BL, Menolasino MJ III. Metastatic penile squamous cell carcinoma to the retroperitoneum in a man with human papillomavirus type 45. J Am Osteopath Assoc 2008;108(6):310-312 
20 Dexeus FH, Logothetis CJ, Sella A, et al. Combination chemotherapy with methotrexate, bleomycin and cisplatin for advanced squamous cell carcinoma of the male genital tract. J Urol 1991;146(5):1284-1287

21 Trabulsi EJ, Hoffman-Censits J. Chemotherapy for penile and urethral carcinoma. Urol Clin North Am 2010;37(3):467-474

22 Hakenberg OW, Protzel C. Chemotherapy in penile cancer. Ther Adv Urol 2012;4(3):133-138
23 Pizzocaro G, Nicolai N, Milani A. Taxanes in combination with cisplatin and fluorouracil for advanced penile cancer: preliminary results. Eur Urol 2009;55(3):546-551

24 Survival Rates for Penile Cancer. Available at: https://www. cancer.org/cancer/penile-cancer/detection-diagnosis-staging/ survival-rates.html. Accessed November 7, 2019 